\title{
Maternity care provider knowledge, attitudes, and practices regarding provision of postpartum intrauterine contraceptive devices at a tertiary center in Ghana
}

\author{
Devon M. Rupley ${ }^{\mathrm{a}, *}$, Emmanuel S.K. Morhe ${ }^{\mathrm{b}}$, Cheryl A. Moyer ${ }^{\mathrm{c}}$, Vanessa K. Dalton ${ }^{\mathrm{d}}$ \\ a Department of Obstetrics and Gynecology, New York Presbyterian/Columbia University Medical Center, New York City, NY, USA \\ b Department of Obstetrics and Gynaecology, Kwame Nkrumah University of Science and Technology, Kumasi, Ghana \\ c Department of Learning Health Sciences, University of Michigan Medical School, Ann Arbor, MI, USA \\ d Department of Obstetrics and Gynecology, University of Michigan Medical School, Ann Arbor, MI, USA
}

\section{A R T I C L E I N F O}

\section{Article history:}

Received 21 April 2014

Received in revised form 30 August 2014

Accepted 21 October 2014

\section{Keywords:}

Contraceptive counseling

Intrauterine device

Postpartum contraception

Training

\begin{abstract}
A B S T R A C T
Objective: To assess knowledge, attitudes, and practices of maternity care providers regarding the provision of postpartum intrauterine contraceptive devices (IUDs) in Komfo Anokye Teaching Hospital (KATH), Kumasi, Ghana. Methods: A descriptive, cross-sectional study was conducted between June 28 and July 15, 2011. Specialists, residents, house officers, and nurse midwives who had been working in the Department of Obstetrics and Gynecology for at least 3 months were included. Self-administered questionnaires assessed formal training, current proficiency in IUD insertion, and attitudes toward postpartum IUD provision. Results: Of 91 providers surveyed, 70 (77\%) reported previous training in contraceptive counseling. Fewer than one in three respondents had ever inserted an IUD: 17 (44\%) of 39 physicians and 9 (17\%) of 52 midwives reported ever having inserted an IUD. A total of 33 (36\%) respondents reported that they would recommend an IUD in the immediate postpartum period. Conclusion: Although most maternity care providers at KATH had received training in contraceptive counseling, few felt confident in their ability to insert an IUD. Further training in postpartum contraceptive management is needed.

(c) 2014 International Federation of Gynecology and Obstetrics. Published by Elsevier Ireland Ltd. All rights reserved.
\end{abstract}

\section{Introduction}

The West African nation of Ghana has a national reproductive health policy with clearly defined targets, standards, and protocols [1]. However, the contraceptive needs of many women in the country remain unmet, especially in the period immediately after delivery [1-3]. In 2003, only $19.3 \%$ of married women reported current use of any modern contraceptive method [2]. Low contraceptive use has been associated with high numbers of unwanted pregnancies, unintended births, and unsafe abortions, which are in turn linked to high maternal and child morbidity and mortality $[4,5]$.

The Copper T 380A intrauterine contraceptive device (IUD) is a safe and effective reversible contraceptive that provides 10 years of protection against pregnancy. Furthermore, it can be inserted in the immediate postpartum period [6,7]. However, less than $1 \%$ of women in Ghana used the Copper T IUD [2]. The low use could be partly due to provider and institutional factors that affect the contraceptive-seeking behavior of women [8]. In recent surveys in South Africa [9,10], family

\footnotetext{
* Corresponding author at: 622 West 168th St., Suite 16-29, New York, NY 10032, USA. Tel.: +1 248345 2570; fax: +1212305 4672 .

E-mail address: dr2777@cumc.columbia.edu (D.M. Rupley).
}

planning providers were found to have poor knowledge about IUDs and to hold incorrect beliefs about IUD risks and client selection.

The immediate postpartum period is an opportune but underused time to counsel women on contraceptive options to prevent future unwanted pregnancies. Effective client education and improvements in access to services could address many perceived barriers to contraceptive uptake in this period [11]. Provider proficiency in carrying out comprehensive education and counseling on postpartum contraception is particularly important in settings where literacy rates are low [12]. In a systematic review, Lopez et al. [13] indicated that education on postpartum contraceptive use is associated with increased contraception use and a reduction in the occurrence of unplanned pregnancies. They further found that both short-term and multiple-contact educational interventions had positive effects on rates of postpartum contraceptive use [13]. These findings underscore the importance of judicious use of the postpartum period as an opportunity to expose women to comprehensive contraceptive information as well as making the method of their choice available to them.

In Ghana, in addition to ensuring healthy infant growth from exclusive breastfeeding, lactational amenorrhea is often promoted as a means of birth control within the first 6 months post partum. Postpartum contraceptives are also offered, including long-acting reversible and permanent methods. Although not free, most contraceptives (including IUDs) 
are generally available at heavily subsidized cost in public and private health institutions. Contraceptive services in Ghana are largely provided by midwives and public health nurses. Physicians, particularly maternity care providers, also take part in contraceptive counseling and education in addition to providing surgical methods of birth control.

The present study was developed to guide the design and implementation of an intervention project to improve postpartum contraceptive service delivery of IUDs in the Komfo Anokye Teaching Hospital (KATH). Its aim was to determine the proportion of maternity care providers who have been trained in contraceptive counseling regarding IUDs, felt confident inserting an IUD, and would recommend immediate postpartum IUD insertion. Additionally, provider knowledge about client selection and risks for IUD use were assessed.

\section{Materials and methods}

A descriptive, cross-sectional survey of maternity care providers was conducted at KATH between June 28 and July 15, 2011. KATH is the second largest tertiary care center in Ghana, and is the training and research center for the College of Health Sciences of the Kwame Nkrumah University of Science and Technology in Kumasi, Ghana. The Department of Obstetrics and Gynecology trains residents, medical students, midwives, nurses, and paramedics, among others. The department has a busy antenatal clinic and oversees more than 1200 deliveries annually. Specialist obstetricians and gynecologists, residents, house officers, and nurse midwives who had been working in the Department of Obstetrics and Gynecology for at least 3 months were eligible to participate in the present study. The study was reviewed and approved by the University of Michigan and Kwame Nkrumah University institutional review boards. Verbal consent was obtained from all participants.

Eligible maternity care providers were contacted by a member of study team while on duty in various units of the department. A printed questionnaire was distributed for self-administration. Individuals had the option to abstain from participating in the study. Completed surveys were placed in a folder and collected from providers by a team member. Once participants completed the questionnaire, contact was not maintained individually. Anonymity was ensured and no specific identifiers were obtained during the survey; questionnaires could not be traced to the participants.

Survey items addressed the respondent's exposure to training and current proficiency in offering IUD services, their attitudes toward postpartum IUD service provision, and recommendation of IUD for different subpopulations of patients. Provider willingness to recommend the use of IUDs for specific subgroups was explored, including women in the immediate postabortion period, nulliparous women, teenagers, women with a history of ectopic pregnancy, women with history of sexually transmitted infection or pelvic inflammatory disease in the last 2 years, women with bacterial vaginosis, and women with HIV infection.

The main outcome measures were the percentage of providers who had been trained and felt confident in offering postpartum contraceptive counseling services and the proportion who would recommend IUDs for different subpopulations of maternity clients. The results of the present study were presented to physicians and midwives of the Department of Obstetrics and Gynecology, and the findings and suggestions were incorporated into the design of the intervention project to improve postpartum IUD service delivery in KATH.

The sample size was calculated with $95 \%$ confidence intervals and 5\% confidence limits, and was determined to be 132 on the basis of the hypothesis that $50 \%$ of providers had been trained and would readily recommend immediate postpartum contraception. Data were entered into Microsoft Excel (Microsoft Inc, Redmond, WA, USA) and then imported into SPSS version 15.0 (SPSS Inc, Chicago, IL, USA) for analysis. In view of the exploratory nature of the present study, calculated statistics were mostly descriptive. When appropriate, Pearson $\chi^{2}$ and ANOVA statistics were used to evaluate differences in opinions of physicians and midwives on IUD insertion in specific subpopulations of clients. $P \leq 0.05$ was considered significant.

\section{Results}

Approximately 200 maternity care providers were eligible to participate, although exact numbers are unknown because residents and midwives rotate through several different sites during training. Approximately one-third of these providers were physicians. A total of 140 surveys were distributed, 91 (65\%) of which were completed after surveys from ineligible providers were excluded. In all, 39 physicians and 52 midwives completed surveys. Table 1 shows their characteristics.

Of the 91 maternity care providers surveyed, more than threequarters had received some training in contraceptive counseling (Table 1). Slightly more than half the respondents reported that they felt comfortable counseling clients on contraception, including almost $60 \%$ of midwives (Table 1 ). More than $90 \%$ of providers discussed IUDs only occasionally or not all during prenatal or postpartum care (Table 1). Overall, less than one-third of providers had ever inserted an IUD, with fewer midwives than physicians reporting previous insertion (Table 1).

Regarding immediate postpartum IUD placement, 33 (36\%) respondents thought it was safe to insert an IUD in the immediate postpartum period, including 16 (41\%) of 39 physicians and 17 (33\%) of 52 midwives $\left(\chi^{2}=2.89 ; P=0.09\right)$. Conversely, almost all respondents would recommend IUD insertion after 6 weeks post partum (Table 2).

Almost half the respondents would not recommend IUD placement to nulliparous women or to teenagers (Table 2). More than half the physicians reported that they would recommend IUD insertion immediately after an abortion, compared with only one-third of midwives (Table 2). Few providers reported that they would recommend IUDs to women with a history of ectopic pregnancy or who had had a pelvic inflammatory disease within the previous 2 years (Table 2 ). Almost half of respondents would recommend an IUD to a woman with HIV (Table 2). Very few reported that they would recommend an IUD to a woman with bacterial vaginosis (Table 2 ).

Table 1

Characteristics, experiences, and views of participants. ${ }^{a}$

\begin{tabular}{|c|c|c|c|}
\hline Variables & $\begin{array}{l}\text { Physicians } \\
(\mathrm{n}=39)\end{array}$ & $\begin{array}{l}\text { Midwives } \\
(\mathrm{n}=52)\end{array}$ & $\begin{array}{l}\text { Total } \\
(\mathrm{n}=91)\end{array}$ \\
\hline Female & $13(33)$ & $52(100)$ & $65(71)$ \\
\hline Male & $26(67)$ & 0 & $26(29)$ \\
\hline \multicolumn{4}{|l|}{ Age, y } \\
\hline Mean \pm SD & $34.0 \pm 7.8$ & $37.3 \pm 13.8$ & $35.9 \pm 11.7$ \\
\hline Median (range) & $31(25-51)$ & $29(22-60)$ & $30(22-60)$ \\
\hline \multicolumn{4}{|c|}{ Length of service at KATH, y } \\
\hline Mean \pm SD & $4.1 \pm 4.7$ & $7.9 \pm 10.1$ & $6.3 \pm 8.3$ \\
\hline Median (range) & $2(0-15)$ & $3(0-35)$ & $30(0-35)$ \\
\hline \multicolumn{4}{|c|}{ Had training in contraception counseling } \\
\hline Yes & $31(79)$ & $39(75)$ & $70(77)$ \\
\hline No & $8(21)$ & $13(25)$ & $21(23)$ \\
\hline \multicolumn{4}{|c|}{$\begin{array}{l}\text { Felt confident counseling on } \\
\text { contraception }\end{array}$} \\
\hline Yes & $18(46)$ & $30(58)$ & $48(53)$ \\
\hline No & $21(54)$ & $22(42)$ & $43(47)$ \\
\hline \multicolumn{4}{|c|}{ Discuss postpartum IUD use } \\
\hline Not at all & $10(26)$ & $4(8)$ & $14(15)$ \\
\hline Occasionally & $25(64)$ & $45(87)$ & $70(77)$ \\
\hline Frequently & $3(8)$ & $2(4)$ & $5(5)$ \\
\hline Very frequently & $1(3)$ & $1(2)$ & $2(2)$ \\
\hline \multicolumn{4}{|l|}{ Ever inserted IUD } \\
\hline Yes & $17(44)$ & $9(17)$ & $26(29)$ \\
\hline No & $22(56)$ & $43(83)$ & $65(71)$ \\
\hline \multicolumn{4}{|c|}{ Feel comfortable inserting IUD ${ }^{\mathrm{b}}$} \\
\hline Yes & $13(76)$ & $5(56)$ & $18(69)$ \\
\hline No & $4(24)$ & $4(44)$ & $8(31)$ \\
\hline
\end{tabular}

Abbreviations: KATH, Komfo Anokye Teaching Hospital; IUD, intrauterine device.

a Values are given as number (percentage) unless indicated otherwise.

b Percentages calculated with the numbers of providers who had ever inserted an IUD. 
Table 2

Maternity care provider attitude toward recommending use of IUDs in specific circumstances. $^{\mathrm{a}}$

\begin{tabular}{|c|c|c|c|}
\hline Recommendations & $\begin{array}{l}\text { Physicians } \\
(\mathrm{n}=39)\end{array}$ & $\begin{array}{l}\text { Midwives } \\
(\mathrm{n}=52)\end{array}$ & $\begin{array}{l}\text { Total } \\
(\mathrm{n}=91)\end{array}$ \\
\hline \multicolumn{4}{|c|}{ Use in nulliparous women } \\
\hline Yes & $22(56)$ & $27(52)$ & $49(54)$ \\
\hline No & $17(44)$ & $25(48)$ & $42(46)$ \\
\hline \multicolumn{4}{|c|}{ Use in immediate postabortion period } \\
\hline Yes & $22(56)$ & $17(33)$ & $39(43)$ \\
\hline No & $17(44)$ & $35(67)$ & $52(57)$ \\
\hline \multicolumn{4}{|l|}{ Use in teenagers } \\
\hline Yes & $17(44)$ & $30(58)$ & $47(52)$ \\
\hline No & $22(56)$ & $22(42)$ & $44(48)$ \\
\hline \multicolumn{4}{|c|}{ Use in women with a previous ectopic pregnancy } \\
\hline Yes & $12(31)$ & $2(4)$ & $14(15)$ \\
\hline No & $27(69)$ & $50(96)$ & $77(85)$ \\
\hline \multicolumn{4}{|c|}{ Use in women who had had an STI within past 2 years } \\
\hline Yes & $10(26)$ & $11(21)$ & $21(23)$ \\
\hline No & $29(74)$ & $39(75)$ & $68(75)$ \\
\hline Unanswered & 0 & $2(4)$ & $2(2)$ \\
\hline \multicolumn{4}{|c|}{ Use in women who had had pelvic inflammatory disease within past 2 years } \\
\hline Yes & $7(18)$ & $7(13)$ & $14(15)$ \\
\hline No & $32(82)$ & $45(87)$ & $77(85)$ \\
\hline \multicolumn{4}{|c|}{ Use in women with HIV infection } \\
\hline Yes & $21(54)$ & $21(40)$ & $42(46)$ \\
\hline No & $18(46)$ & $31(60)$ & $49(54)$ \\
\hline \multicolumn{4}{|c|}{ Use in women with bacterial vaginosis } \\
\hline Yes & $4(10)$ & $4(8)$ & $8(9)$ \\
\hline No & $34(87)$ & $47(90)$ & $81(89)$ \\
\hline Unanswered & $1(3)$ & $1(2)$ & $2(2)$ \\
\hline \multicolumn{4}{|c|}{ Use in immediate postpartum period } \\
\hline Yes & $16(41)$ & $17(33)$ & $33(36)$ \\
\hline No & $18(46)$ & $23(44)$ & $41(45)$ \\
\hline Unanswered & $5(13)$ & $12(23)$ & $17(19)$ \\
\hline \multicolumn{4}{|c|}{ Use after 6 weeks post partum } \\
\hline Yes & $37(95)$ & $49(94)$ & $86(95)$ \\
\hline No & $2(5)$ & $3(6)$ & $5(5)$ \\
\hline
\end{tabular}

Abbreviations: IUD, intrauterine device; STI, sexually transmitted infection.

a Values are given as number (percentage).

\section{Discussion}

Although most (77\%) maternity care providers surveyed at KATH in the present study reported having had any training in contraceptive counseling, only approximately half felt comfortable counseling individuals about contraception. More than $90 \%$ never or only occasionally discussed use of IUDs in the postpartum period with clients. Most respondents also held misconceptions about the use of IUDs in various subpopulations. Perhaps most surprisingly, few respondents felt confident about inserting an IUD.

Provider bias regarding the appropriateness of IUD use among subpopulations of women continues to be a major barrier to IUD uptake. Evidence indicates that IUDs are safe and well tolerated in nulliparous women [14]. However, many healthcare providers have misconceptions about the safety of an IUD in nulliparous women $[14,15]$. This observation is clearly supported by the present finding that half of maternity care providers surveyed were unwilling to recommend the use of an IUD to nulliparous women.

Furthermore, it is well established that IUD insertion immediately after induced or spontaneous abortion is safe and practical $[16,17]$. Thus, the low willingness of the respondents to recommend IUD for this subpopulation of women implies that most maternity care providers in the department did not have up-to-date knowledge and skill in provision of IUD services. The findings of the present study also support the observation that, despite evidence that IUD-associated pelvic inflammatory disease and sexually transmitted infections are not prevalent in West Africa, many providers are not well informed [18]. Many providers in the present study still held onto the misconception that use of IUDs in women with a history of sexually transmitted infections or pelvic inflammatory disease should be avoided. Notably, the opinions and attitudes of physicians and midwives were similar. Thus, in planning interventions, both physicians and midwives should be targeted.

The present study has several limitations. We surveyed providers at only one site and within one specialty; further study of providers at other facilities throughout West Africa and in other specialties in which contraception is discussed would provide a more accurate representation of knowledge and practices regarding IUDs in this region. Additionally, because of survey length constraints, the specific types of training on IUDs previously received by providers could not be addressed. This area should be explored further at KATH and elsewhere in the future.

The overall rate of counseling on immediate postpartum contraception and which other immediate postpartum contraceptive options were being offered to patients were not assessed. This information would provide a broader understanding of current contraceptive counseling within the immediate postpartum period, and could help to focus further provider training. Furthermore, the present study was focused on providers only; additional studies of patient knowledge and attitudes towards IUDs generally and in the immediate postpartum period specifically should be undertaken as the next step in determining barriers to increasing use of long-acting reversible contraceptives in this population. Finally, because of time and scheduling limitations, the desired sample size of 132 was not achieved; additional study participants would increase the strength of the study.

In conclusion, the present study's findings demonstrate gaps in the knowledge and skill regarding provision of IUD services at KATH. These gaps need to be addressed to enable providers to effectively educate and serve clients who need postpartum family planning [19]. The data support the call for interventions to improve provider knowledge, information, and skills through strengthening of both in-service and preservice education programs. Strengthening of preservice training in family planning and regular updates to address misconceptions about IUDs and other long-term contraceptives are needed. A short-term intervention to improve knowledge and skill of providers is needed at KATH.

\section{Acknowledgments}

An anonymous donor funded this project through the International Family Planning Fellowship Program. The International Institute at the University of Michigan also provided financial support.

\section{Conflict of interest}

V.K.D received funding from McNeil to participate in a one-time advisory committee in December 2012. The other authors have no conflicts of interest.

\section{References}

[1] National Population Council, Government of Ghana. National Population Policy (revised edition, 1994). http://www.npc.gov.gh/assets/NationalPopulationPolicyata Glance.pdf. Published 1994. Accessed October 19, 2014.

[2] Ghana Statistical Service, Noguchi Memorial Institute for Medical Research, ORC Macro. Ghana Demographic and Health Survey 2003. http://dhsprogram.com/ pubs/pdf/FR152/FR152.pdf. Published September 2004. Accessed October 19, 2014.

[3] Ghana Statistical Service, IFC Macro. Ghana Demographic and Health Survey 2008. http://dhsprogram.com/pubs/pdf/FR221/FR221[13Aug2012].pdf. Published September 2009. Accessed October 19, 2014.

[4] Ahiadeke C. Incidence of induced abortion in Southern Ghana. Int Fam Plan Perspect 2001;27(2):96-101.

[5] Baird TL, Billings DL, Demuyakor B. Community education efforts enhance postabortion care program in Ghana. Am J Public Health 2000;90(4):631-2.

[6] Osei I, Birungi H, Addico G, Askew I, Gyapong JO. What happened to the IUD in Ghana? Afr J Reprod Health 2005;9(2):76-91.

[7] Grimes DA, Lopez LM, Schlulz KF, Van Vliet HA, Stanwood NL. Immediate postpartum insertion of intrauterine devices. Cochrane Database Syst Rev 2010;12(5): CD003036.

[8] Sable MR, Libbus MK, Chiu JE. Factors affecting contraceptive use in women seeking pregnancy tests: Missouri, 1997. Fam Plan Perspect 2000;32(3):124-31. 
[9] van Zijl S, Morroni C, van der Spuy ZM. A survey to assess knowledge and acceptability of the intrauterine device in the Family Planning Services in Cape Town, South Africa. J Fam Plann Reprod Health Care 2010;36(2):73-8.

[10] Gutin SA, Mlobeli R, Moss M, Buga G, Morroni C. Survey of knowledge, attitudes and practices surrounding the intrauterine device in South Africa. Contraception 2011; 83(2):145-50.

[11] Scott A, Glasier A. Evidence based contraceptive choices. Best Pract Res Clin Obstet Gynaecol 2006;20(5):665-80.

[12] Konje JC, Oladini F, Otolorin EO, Ladipo OO. Factors determining the choice of contraceptive methods at the Family Planning Clinic, University College Hospital, Ibadan, Nigeria. Br J Fam Plann 1998:24(3):107-10.

[13] Lopez LM, Hiller JE, Grimes DA. Education for contraceptive use by women after childbirth. Cochrane Database Syst Rev 2010;1:CD001863.

[14] Brown WM, Trouton K. Intrauterine device insertions: which variables matter? J Fam Plann Reprod Health Care 2014;40(2):117-21.
[15] Tyler CP, Whiteman MK, Zapata LB, Curtis KM, Hillis SD, Marchbanks PA. Health care provider attitudes and practices related to intrauterine devices for nulliparous women. Obstet Gynecol 2012;119(4):762-71.

[16] Steenland MW, Tepper NK, Curtis KM, Kapp N. Intrauterine contraceptive insertion postabortion: a systematic review. Contraception 2011;84(5):447-64.

[17] Grimes DA, Lopez LM, Schulz KF, Stanwood NL. Immediate postabortal insertion of intrauterine devices. Cochrane Database Syst Rev 2010;6:CD001777.

[18] Stanback J, Shelton JD. Pelvic inflammatory disease attributable to the IUD: modeling risk in West Africa. Contraception 2008;77(4):227-9.

[19] Eliason S, Baiden F, Quansah-Asare G, Graham-Hayfron Y, Bonsu D, Phillips J, et al. Factors influencing the intention of women in rural Ghana to adopt postpartum family planning. Reprod Health 2013;10:34 